\title{
Analisis Indeks Harga Saham Gabungan (Ihsg) Menggunakan Metode Wavelet Thresholding
}
(Analysis of Combined
Stock Price
Index
(Cspi)
using
Wavelet Thresholding Method)

\author{
Zahra Awaliya Fauziah* ${ }^{* 1}$, Junaidi ${ }^{1}$ dan Lilies Handayani ${ }^{1}$ \\ ${ }^{1}$ Program Studi Statistika, Jurusan Matematika, Fakultas MIPA, Universitas Tadulako, Jl. Soekarno Hatta Km 9 Tondo \\ Palu Sulawesi Tengah 94118.
}

Keywords: $I C I$, Wavelet

Thresholding, Time Series

Keywords: IHSG, Wavelet Thresholding, Time Series

\footnotetext{
* Coresponding Author: zahra.awaliyah@yahoo.com
}

\begin{abstract}
Stock is one type of long-term investment in the capital market. The stock movement indicator that is most often used in analysis by investors is the Indonesia Composite Index $(\mathrm{ICl})$. ICl data is a variety of time series data, so it can be analyzed using forecasting. One forecasting method that can be used is the wavelet thresholding method. The wavelet threshold can analyze stationary, nonstationary, and nonlinear time series data by producing smooth estimates. The wavelet threshold has a wavelet filter and threshold parameters and threshold functions that can be used in analyzing. In this study MSE was assessed from several wavelet filters namely haar, daubechies, and coiflets filters at levels 1 to 7 with the thresholding function namely soft thresholding and thresholding parameters, namely minimax thresholding and sure thresholding. The data used is IHGS data in 2018 totaling 240 data. Based on the data analysis performed, MSE was obtained which means that the best filter provided in order 2 wavelet coiflet filter at level 2 and thresholding parameter is sure of thresholding with MSE value of 0.0094 .
\end{abstract}

\footnotetext{
Abstrak

Saham merupakan salah satu jenis investasi jangka panjang dalam pasar modal. Indikator pergerakan saham yang paling sering digunakan dalam menganalisis oleh para investor yaitu indeks harga saham gabungan (IHSG). Data IHSG merupakan data runtun waktu yang fluktuasinya beragam, sehingga dapat dianalisis menggunakan peramalan. Salah satu metode peramalan yang dapat digunakan yaitu metode wavelet thresholding. Wavelet thresholding dapat menganalisis data runtun waktu stasioner, nonstasioner, dan nonlinear dengan menghasilkan estimasi yang mulus. Wavelet thresholding memiliki filter wavelet dan parameter thresholding serta fungsi thresholding yang dapat digunakan dalam menganalisis data runtun waktu. Pada penelitian ini dilakukan perbandingan nilai MSE dari beberapa filter wavelet yaitu filter haar, daubechies, dan coiflet pada level 1 sampai 7 dengan fungsi thresholding yaitu soft thresholding dan parameter thresholding yaitu minimax thresholding dan sure thresholding. Data yang digunakan yaitu data IHGS pada tahun 2018 sebanyak 240 data. Berdasarkan analisa data yang dilakukan, diperoleh kesimpulan bahwa MSE terkecil yang menunjukkan filter wavelet terbaik terdapat pada filter wavelet coiflet orde 2 pada level 2 dan parameter thresholding yaitu sure thresholding dengan nilai MSE sebesar 0.0094.
} 


\section{Latar Belakang}

Saham merupakan salah satu instrumen investasi jangka panjang di pasar modal yang paling populer. Salah satu parameter pergerakan harga saham yang biasa digunakan oleh para investor sebagai acuan yaitu indeks harga saham gabungan (IHSG). IHSG merupakan suatu nilai untuk mengukur kinerja saham yang tercatat dipasar modal (bursa efek) (Hadi, 2015). Performa IHSG telah mengalami kenaikan sekitar $1143 \%$ dari posisi 401 menjadi 4593 dalam kurun waktu 18 tahun, sejak tahun 1997-2015 (OJK, 2016). Perhitungan IHSG dilakukan setiap hari yaitu setelah penutupan perdagangan (Tauryawati dan Irawan, 2014). Data IHSG merupakan data runtun waktu yang memiliki fluktuasi yang sangat beragam. Peramalan data IHSG dapat dilakukan dengan beberapa metode seperti Moving Average, ARMA, ARIMA, wavelet, dan lain sebagainya.

Wavelet merupakan fungsi transformasi yang secara otomatis memotong data kedalam beberapa bagian berbeda dan mempelajari masing-masing komponen dengan resolusi yang sesuai dengan skalanya. Transformasi wavelet merupakan teknik dekomposisi multiresolusi untuk mengatasi masalah pemodelan yang menghasilkan sinyal representasi lokal yang baik pada domain waktu dan domain frekuensi (Lestari dan Subanar, 2015). Pada analisis wavelet terdapat metode yang biasa digunakan dalam melakukan peramalan yaitu metode wavelet thresholding.

Metode wavelet thresholding merupakan suatu alternatif dalam analisis data runtun waktu karena dianggap mampu menghasilkan estimasi yang mulus dengan mereduksi noise (gangguan). Metode wavelet thresholding dapat diterapkan pada data runtun waktu stasioner, nonstasioner dan nonlinier (Wibowo dkk, 2012).

Beberapa penelitian yang menggunakan peramalan IHSG diantaranya adalah Puspitasari dkk (2012), menggunakan analisis indeks harga saham gabungan (IHSG) dengan menggunakan model regresi kernel. Tauryawati dan Irawan (2014), menggunakan perbandingan metode fuzzy time series cheng dan metode box-jenkins untuk memprediksi IHSG. Sanusi (2017), menggunakan pemodelan volatilitas long memory pada IHSG menggunakan model fiegarch. Nafisah (2017), menggunakan peramalan indeks harga saham gabungan menggunakan model ARIMA dan metode fuzzy time series.

Beberapa penerapan metode wavelet thresholding runtun waktu telah dilakukan. Farima dan Utami
(2018), menggunakan peramalan nilai tukar dolar Amerika terhadap Indonesia dengan menggabungkan dua metode yaitu maximal overlap discrete wavelet transform (MODWT) dan autoregressive moving average (ARMA) dan diperoleh nilai MAPE yang kecil. Kusumaningrum dkk (2017), menganalisis data runtun waktu nilai tukar rupiah terhadap dollar US menggunakan metode wavelet thresholding dengan Maximal Overlap Discrete wavelet Transform (MODWT) dan analisis multiresolusi (MRA) yang membandingkan model terbaik berdasarkan nilai MSE terkecil dan diperoleh hasil MSE dari MODWT lebih kecil. Wibowo (2012), menggunakan analisis data runtun waktu yang membandingkan hasil yang diperoleh dengan metode ARIMA dan wavelet trhresholding berdasarkan nilai MSE terkecil dan hasil estimasi dan nilai MSE dari wavelet thresholding yang diperoleh lebih mulus dan kecil dibandingkan dengan metode ARIMA.

Penelitian ini akan membahas penggunaan metode wavelet thresholding dalam menganalisis data runtun waktu indeks harga saham gabungan (IHSG) pada tahun 2018 dengan membandingkan dua parameter thresholding yaitu minimax threshold dan adaptive threshold pada tiga filter wavelet yaitu haar, daubechies, dan coeflet menggunakan fungsi soft thresholding dengan membandingkan nilai MSE terkecil.

\section{Bahan dan Metode}

Data yang digunakan dalam penelitian ini merupakan data sekunder yang diperoleh dari website resmi Indonesia Stock Exchange (IDX) yaitu data indeks harga saham gabungan (IHSG) pada tahun 2018, sebanyak 240 data.

\section{Analisis Data}

Langkah-langkah dalam menganalisis data:

1. Mengumpulkan data indeks harga saham gabungan (IHSG) tahun 2018.

2. Ekstraksi ciri menggunakan filter haar, daubechies (db1, db2, db3, db4, db5, db6, db7, db8, db9, dan $\mathrm{db} 10$ ), dan coeflet (coif1, coif2, coif3, coif4, dan coif5) pada level 1 sampai 7 .

3. Denoising data menggunakan fungsi thresholding (soft thresholding) dan parameter thresholding (minimax threshold dan adaptive threshold (sure thresholding)).

4. Dekomposisi data.

5. Menentukan nilai MSE terkecil.

6. Pengambilan keputusan. 


\section{Hasil dan Pembahasan}

Analisis wavelet thresholding menggunakan filter wavelet haar, daubechies ( $\mathrm{db} 1, \mathrm{db} 2, \mathrm{db} 3, \mathrm{db} 4, \mathrm{db} 5$, db6, db7, db8,db9, dan db10), dan coiflet (coif1, coif2, coif3, coif4, dan coif5) pada level 1 sampai 7 dengan fungsi thresholding yaitu soft thresholding dan parameter thresholding yaitu minimax thresholding dan sure thresholding. Filter wavelet terbaik dalam mengestimasikan data IHSG dapat ditunjukkan oleh nilai MSE terkecil yaitu nilai mendekasti 0 . Nilai MSE didapatkan menggunakan bantuan software matlab R2019a dan diperoeh hasil sebagai berikut:

Tabel 1. Nilai MSE Pada Filter Wavelet Haar

\begin{tabular}{ccc}
\hline & sure & minimax \\
\hline haar(1) & 4.5850 & 4.5850 \\
haar(2) & 0.0625 & 2.2821 \\
haar(3) & 40.7031 & 2.7950 \\
haar(4) & 81.3437 & 3.0591 \\
haar(5) & 81.3437 & 3.1878 \\
haar(6) & $1,297.6$ & 3.2561 \\
haar(7) & 4,858 & 3.2854 \\
\hline
\end{tabular}

Perbandingan nilai MSE menggunakan Filter wavelet haar dengan parameter sure dan minimax thresholding yang ditunjukkan pada Tabel 1, dapat diketahui bahwa nilai MSE pada parameter sure thresholding memiliki nilai yang relatif jauh disetiap levelnya, sedangkan nilai MSE pada minimax thresholding relatif dekat disetiap levelnya. Hal tersebut dapat dilihat dari nilai tertinggi dan terendah pada masing-masing parameter. Pada parameter sure thresholding memiliki nilai tertinggi sebesar 4,858 berada pada level 7 dan nilai terendahnya sebesar 0.0625 berada pada level 2 . Pada parameter minimax thresholding memiliki nilai tertinggi sebesar 4.5850 pada level 1 dan nilai terendah sebesar 2.2821 pada level 2. Berdasarkan nilai terendah dari kedua parameter tersebut, dapat diketahui bahwa nilai MSE terendah berada pada parameter sure thresholding. Sehingga dapat disimpukan bahwa filter wavelet haar terbaik dalam mengestimasi data IHSG yaitu berada pada level 2 pada parameter sure thresholding karena akan menghasilkan nilai data ramalan yang mendekati nilai data IHSG aktual.

Perbandingan nilai MSE terkecil seperti yang ditunjukkan pada Tabel 2, dapat diketahui bahwa nilai MSE terkecil pada filter wavelet haar, daubechies, dan coiflet berada pada level 2 dengan parameter sure thresholding dan nilai MSE terbesar dari yang terkecil berada pada filter coiflet orde 1 dengan parameter sure thresholding yaitu sebesar 5.0638. Sehingga filter wavelet terbaik dalam mengestimasikan data IHSG yaitu filter wavelet coiflet orde 3 pada level 2 dan parameter sure thresholding dengan nilai MSE terkecil yaitu 0.0094 .

Nilai MSE terkecil pada filter wavelet haar, daubechies, dan coiflet disetiap orde dari level 1 sampai level 7 yang dapat dirangkum sebagai berikut:

Tabel 2. Nilai MSE terkecil pada setiap orde filter wavelet

\begin{tabular}{ccccc}
\hline $\begin{array}{c}\text { Filter } \\
\text { Wavelet }\end{array}$ & Orde & Level & \multicolumn{2}{c}{ Nilai MSE } \\
\cline { 4 - 5 } & & & SURE & Minimax \\
\hline Haar & & 2 & 0.0625 & 2.2821 \\
Daubechies & 1 & 2 & 0.0625 & 2.2821 \\
Daubechies & 2 & 2 & 0.4710 & 2.2992 \\
Daubechies & 3 & 2 & 0.3522 & 2.2871 \\
Daubechies & 4 & 2 & 0.3705 & 2.3197 \\
Daubechies & 5 & 2 & 0.0271 & 2.2788 \\
Daubechies & 6 & 2 & 0.1638 & 2.2957 \\
Daubechies & 7 & 2 & 0.5153 & 2.3282 \\
Daubechies & 8 & 2 & 0.5873 & 2.2939 \\
Daubechies & 9 & 2 & 0.0882 & 2.3529 \\
Daubechies & 10 & 2 & 0.7683 & 2.3847 \\
Coiflet & 1 & 2 & 5.0638 & 2.3192 \\
Coiflet & 2 & 2 & 0.3104 & 2.3243 \\
Coiflet & 3 & 2 & 0.0094 & 2.2703 \\
Coiflet & 4 & 2 & 0.0134 & 2.3342 \\
Coiflet & 5 & 2 & 0.0144 & 2.3379 \\
\hline
\end{tabular}

Analisis data IHSG juga bisa dilihat pada grafik yang dihasilkan oleh data ramalan dari setiap filter wavelet. Semakin dekat data hasil ramalan dengan data IHSG aktual, maka semakin baik filter tersebut dalam mengestimasi. Perbandingan data IHSG dan hasil ramalan dapat dilihat pada Gambar 1 dan 2.

Grafik perbandingan data IHSG aktual dan hasil ramalan menggunakan filter haar yang ditunjukkan pada Gambar 1 memperlihatkan bahwa grafik data hasil ramalan (garis orange) dan pergerakan grafik approsimaksinya (garis putus-putus) masih memiliki rentang jarak yang jauh dengan data IHSG aktual (garis biru). Pada Gambar 2, grafik data IHSG aktual (garis biru), hasil ramalan (garis orange), dan aprosimaksi (garis putus-putus) menggunakan filter coiflet orde 3 pada level 2 berada di satu garis yang sama dan saling tumpang-tindih. 


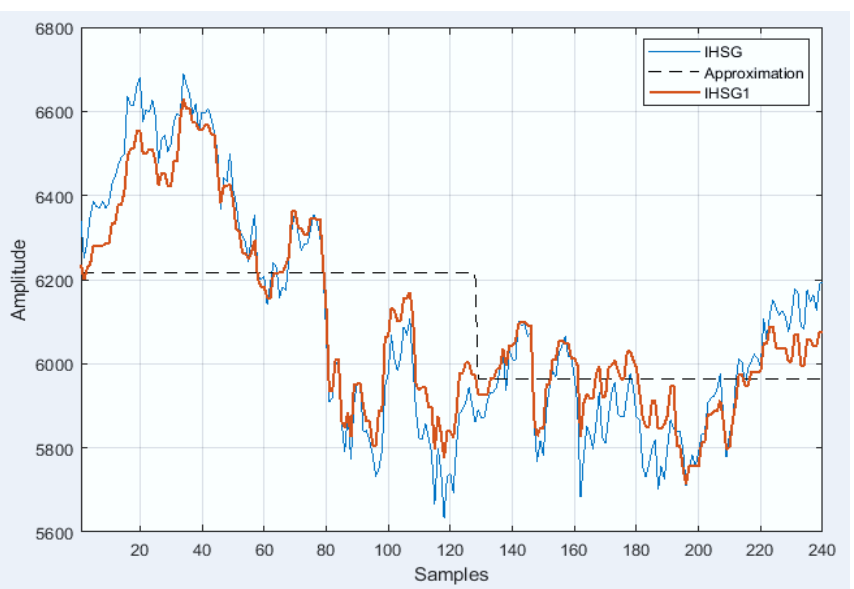

Gambar 1. Grafik perbandingan data IHSG dan hasil ramalan filter haar level 7

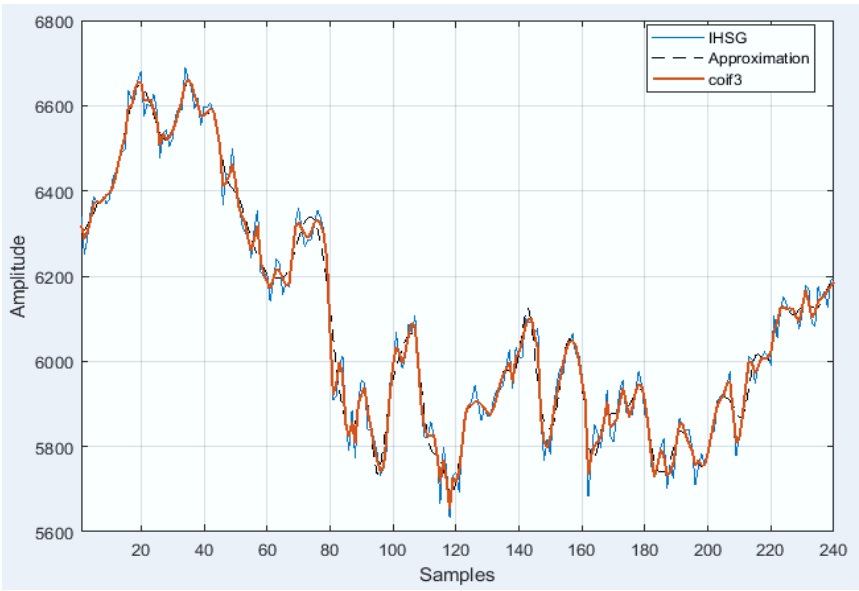

Gambar 2. Grafik perbandingan data IHSG dan hasil ramalan filter coif3 level 2

Berdasarkan Gambar 1 dan 2, dapat disimpukan bahwa data hasil ramalan menggunakan filter wavelet coiflet orde 3 level 2 lebih baik dibandingkan filter wavelet haar level 7 maupun filter lainnya karena plot hasil ramalannya lebih mendekati data IHSG aktualnya.

\section{KESIMPULAN}

Analisis indeks harga saham gabungan (IHSG) tahun 2018 menggunakan metode wavelet thresholding dengan filter wavelet haar, daubechies (db1, db2, db3, $\mathrm{db} 4, \mathrm{db} 5, \mathrm{db} 6, \mathrm{db} 7, \mathrm{db} 8, \mathrm{db} 9$, dan db10), dan coiflet (coif1, coif2, coif3, coif4, dan coif5) pada level 1 sampai 7 dengan membandingkan 2 parameter thresholding yaitu minimax thresholding dan sure thresholding. Filter wavelet dan parameter thresholding terbaik dapat ditunjukkan dengan nilai mse terkecil.

Berdasarkan hasil yang didapatkan, data hasil ramalan terbaik yaitu filter wavelet yang berada pada level 2 dan parameter thresholding yaitu sure thresholding.
Sedangkan filter wavelet terbaik dalam mengestimasikan data IHSG yaitu filter wavelet coiflet orde 2, hal tersebut ditunjukkan oleh nilai mse terkecil yaitu sebesar 0.0094. Perbandingan plot data IHSG aktual dan hasil ramalan menggunakan coiflet orde 2 juga menunjukkan kemiripan karena plot data hasil ramalan mendekati plot data asli.

\section{Daftar Pustaka}

[OJK] Otoritas Jasa Keuangan. (2016). Pasar Modal. Jakarta: Otoritas Jasa Keuangan.

Farima, V.A. dan Utami, H. (2018). Peramalan Nilai Tukar Dolar Amerika terhadap Indonesia dengan Model Maximal Overlap Discrete Wavelet Transform-Autoregressive Moving Average. Yogyakarta: Jurnal Statistika.

Hadi, N. (2015). Pasar Modal Edisi 2. Yogyakarta: Graha IImu.

Kusumaningrum, D.A., Suparti, dan Maruddani, D. A. I. (2017). Analisis data Runtun Waktu Menggunakan Metode Wavelet Thresholding dengan Maximal Overlap Discrete Transform. Semarang: Jurnal Gaussian.

Lestari, V.N. dan Subanar. (2015). Transformasi Wavelet Diskret untuk Data Time Series. Yogyakarta: Seminar Nasional Matematika dan Pendidikan Matematika UNY.

Nafisah, A. (2017). Peramalan Indeks Harga Saham Gabungan Menggunakan Model Arima dan Metode Fuzzy Time Series. Bogor: Institut Pertanian Bogor.

Ogden, R. T. (1997). Essential Wavelet for Statistical Applications and Data Analysis. Boston: Birkhauser Boston.

Percival, D.B., dan Walden, A.T. (2000). Wavelet Methods for Time Series Analysis. New York: Cambridge University Press.

Puspitasari, I., Suparti, dan Wilandari, Y. (2012). Analisis Indeks Harga Saham Gabungan (IHSG) dengan Menggunakan Model Regresi Kernel. Semarang: Jurnal Gaussian.

Sanusi, M.A. (2017). Pemodelan Volatilitas Long Memory pada Indeks Harga Saham Gabungan (IHSG) Menggunakan Model Fiegarch. Bogor: Institut Pertanian Bogor.

Sunariyah. (2003). Pengantar Pengetahuan Pasar Modal. Yogyakarta: UPP AMP YKPN.

Suparti, Mustofa, A. dan Rusgiyono, A. (2007). Estimasi Regresi Wavelet Thresholding dengan 
Metode Bootstrap. Jurnal Matematika: 10(2): 43-

50.

Tauryawati, M.L. dan Irawan, M.I.(2014). Perbandingan Metode Fuzzy Time Series Cheng dan Metode Box-Jenkins untuk Memprediksi IHSG. Surabaya: Jurnal Sains dan Seni Pomits.
Wardah, S. dan Iskandar. (2016). Analisis Peramalan Penjualan Produk Keripik Pisang Kemasan Bungkus. Tembilahan: Universitas Islam Indragiri Wibowo, Y.A., Suparti, dan Tarno. (2012). Analisis Data Runtun Waktu Menggunakan Metode Wavelet Thresholding. Semarang: Jurnal Gaussian. 